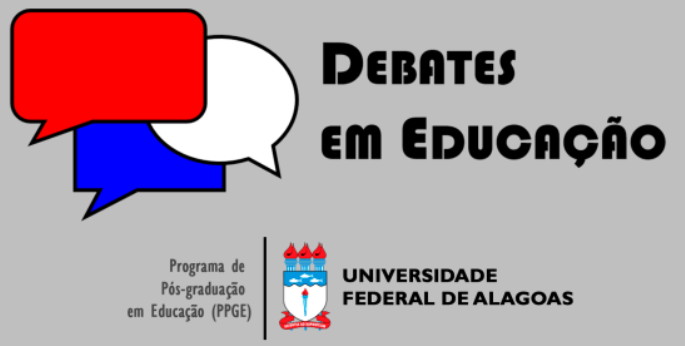

ISSN Eletrônico 2175-6600

Vol. 10 | No. 21 | Maio/Ago. | 2018

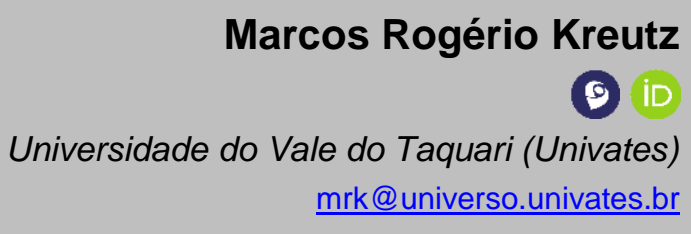

Neli Galarce Machado

(9) iD

Universidade do Vale do Taquari (Univates) ngalarce@univates.br

\section{APRENDIZAGENS ATIVAS: HISTÓRIA REGIONAL E DOCENTES DA EDUCAÇÃO BÁSICA}

\section{RESUMO}

O ensino da História Regional ou Local normalmente impõe restrições aos docentes da Educação Básica, especialmente àqueles que conduzem as aulas de História. A falta de material didático e a insuficiência de uma formação complementar do professor são algumas das dificuldades. O propósito desse artigo é apresentar uma ação educativa na área de História, destinada aos professores da Educação Básica que atuam na região política Vale do Taquari, Rio Grande do Sul. O objetivo da ação foi proporcionar debates, diálogos, material didático e oficinas abordando a temática, o povoamento pré e pós-contato com o europeu no referido território. O caminho metodológico seguido para esse artigo foi a narrativa histórica a partir de revisão bibliográfica e descritiva das ações educativas. Foram atendidos 205 professores do Ensino Fundamental e Médio da rede pública e privada.

Palavras-chave: Ensino. História Regional. Professores.

\section{ACTIVE LEARNING: REGIONAL HISTORY AND TEACHERS OF BASIC EDUCATION}

\begin{abstract}
The Regional or Local History teaching usually imposes restrictions on Basic Education teachers, specially the teachers who teach History classes. The lack of teaching materials and the lack of complementary teacher training are some of the difficulties. This article aims to present an educative action in the History field for teachers of the Basic Education, who work in Taquari Valley, Rio Grande do Sul. The objective of the action was to provide discussions, dialogues, teaching materials and workshops explaining about the pre and post contact with the European in that territory. The methodological path followed for this article were the historical narrative from a bibliographical and descriptive review of educational actions. Two hundred and five teachers from Elementary, Middle and High School from the public and private schools were attended.
\end{abstract}

Keywords: Teaching. Regional History. Teachers.

Submetido em: 06/12/2017

Aceito em: 13/08/2018

DOI: $10.28998 / 2175-6600.2018 v 10 n 21 p 356-372$ 


\section{INTRODUÇÃO}

O professor que atende a Educação Básica para mediar uma prática pedagógica com qualidade, especialmente no campo das Ciências Humanas, depende de uma série de fatores para conduzir um processo de ensino e aprendizagens na busca de reconfigurações da crítica social. Além de fatores, como uma remuneração digna, uma jornada justa de trabalho, uma boa estrutura física da escola, o docente necessita ter em mãos material didático com conteúdo adequado do tema que vai abordar em sala de aula, bem como ter conhecimento e domínio sobre o mesmo.

Nesse contexto, professores de História que atendem a Educação Básica ao ministrar suas aulas para os estudantes abordando a História Regional e Local, pré e póscontato com o colonizador europeu no Brasil, se deparam com uma dificuldade: a falta de material didático que aborde temas específicos de determinada região ou de um local, e, em algumas situações o seu desconhecimento do referido tema.

Como o livro didático é uma das principais ferramentas que os professores utilizam em sala de aula, o mesmo poderia suprir essa carência. Entretanto, o livro não contempla todos os fatos que envolvem a formação política, econômica e social, bem como as ações de atores envolvidos, das regiões de algum estado ou de um território específico, ou seja, a História Regional e Local.

Outro aspecto que dificulta o ensino de História e demais disciplinas, é a formação do professor. No Brasil, especialmente em regiões afastadas dos grandes centros de investigações científicas, os docentes limitam-se a estudar somente durante o curso de graduação e consideram-se aptos a conduzir o conteúdo após a conclusão do mesmo, sem se preocupar com o aperfeiçoamento e qualificação por meio da formação continuada. Muitas vezes, os docentes também não são incentivados por parte das gestões educacionais locais.

Além disso, ainda se percebe um distanciamento entre academia e escola. No Brasil são desenvolvidas inúmeras pesquisas na área de História, Arqueologia, entre outras, cujos resultados muitas vezes, não perpassam pelas escolas. O conhecimento produzido nas instituições de ensino superior poderia ser mais explorado, revertido para o ensino em sala de aula. O conhecimento gerado pode ser oportunizado aos docentes dos educandários da Educação Básica, pois ao mesmo tempo que são divulgadas as pesquisas acadêmicas, aproxima-se ainda mais a academia com a escola.

Diante desses fatores que podem interferir no desempenho do professor, são necessárias ações que atenuem essas dificuldades impostas. O ensino da História 
Regional e Local, bem como a Educação Patrimonial são instrumentos que podem impactar positivamente para a melhoria das aulas dos docentes que ministram disciplinas na área de Ciências Humanas, em especial a disciplina de História.

Pensando nisso e nas situações que norteiam a tarefa de ensinar dos professores, e, especialmente a carência de estudos regionais foi desenvolvido um projeto, contemplando a História Regional. Assim, o artigo tem como objetivo descrever o projeto "Educação Patrimonial: difusão do conhecimento, valorização e desenvolvimento social", e seus resultados, aplicado entre agosto de 2016 a julho de 2017, no âmbito do Programa de Pós-Graduação em Ensino da Universidade do Vale do Taquari, Lajeado/RS. O mesmo foi destinado aos professores da área de Ciências Humanas, Educação Básica, que atuam em escolas públicas e privadas dos municípios que compõem a região Vale do Taquari, localizada no centro leste do Estado do Rio Grande do Sul.

O projeto desenvolvido procurou minimizar as dificuldades encontradas pelos professores da área que atuam na Educação Básica e que participaram das atividades, no sentido de disponibilizar a eles, o conhecimento produzido na academia.

A partir das ações educativas e do projeto em si, desenvolveu-se o texto a partir da narrativa histórica, considerando a análise diacrônica e sincrônica das referências usadas para ampliar o discurso acerca do ensino da História Regional (LE GOFF, 1990; CHESNEAUX, 1995; ARÓSTEGUI, 2006).

\section{2 “NEM TUDO SÃO FLORES”: PERCALÇOS DOS PROFESSORES NO OFÍCIO DE ENSINAR}

Quando se ensina a História e se quer abordar o contexto da comunidade na qual os estudantes estão inseridos, enfrenta-se percalços, situações comuns no ofício de ensinar, entre elas: a necessidade de um bom material didático; um aprimoramento constante, a fim de atualizar o conhecimento do docente, uma vez que as ciências são dinâmicas, novas informações surgem a cada dia; e por fim, os livros didáticos não conseguem abarcar a história política, social e econômica de toda sociedade brasileira.

Entende-se por material didático todo e qualquer recurso para auxiliar no ensino aprendizagem do conteúdo proposto, para ser aplicado pelo professor a seus alunos, no dia a dia da escola, podendo ser do mais simples, como uma barra de giz, a lousa, o livro didático, textos impressos, até materiais sofisticados (FISCARELLI, 2007; SOUZA, 2007).

A utilização de recursos didáticos, segundo Souza (2007, p. 112), no processo de ensino - aprendizagem são importantes para que o estudante assimile o conteúdo, "[...] 
desenvolvendo sua criatividade, coordenação motora e habilidade ao manusear objetos diversos que poderão ser usados pelo professor na aplicação de suas aulas".

$\mathrm{Na}$ opinião da maioria dos docentes, os materiais didáticos bem elaborados dinamizam a aula. Sua utilização implica facilitar o aprendizado, atrair, motivar e despertar o interesse do estudante para a aula. Os professores percebem, ao utilizar materiais didáticos, a oportunidade de proporcionar uma participação ativa dos estudantes durante as aulas (FISCARELLI, 2007).

O ideal com o uso de material didático é de que o mesmo propicie ao estudante, o estímulo à pesquisa e a novos conhecimentos, para fazer com que o estudante adquira a cultura investigativa (SOUZA, 2007). O material didático pode ser inovador, entretanto, o uso de qualquer tipo de recurso não é suficiente para que o processo de ensinoaprendizagem tenha sucesso. A formação e o contínuo aperfeiçoamento do professor também são fundamentais.

A formação continuada dos professores torna-se relevante, uma vez que não basta concluir o curso de graduação, é necessário um contínuo aprimoramento de seus conhecimentos. Parcela de professores, após concluir o curso superior, não buscam nenhum tipo de aperfeiçoamento. Participam eventualmente de algum congresso ou seminário sem, no entanto, se aprofundar na área. A participação nesses eventos, muitas vezes, nada mais é que uma mera formalidade, provar que esteve participando de algum curso de formação continuada. Daí a importância de um contínuo aperfeiçoamento após conclusão do curso superior.

Os cursos de formação continuada permitem a atualização dos professores, uma vez que a graduação não comporta todo conhecimento. Devem tratar de maneira especial os conteúdos específicos, o que garante a assimilação de conhecimentos em determinadas áreas. Devem proporcionar oportunidades que estimulem o desenvolvimento pessoal (CUNHA; KRASILCHIK, 2000).

Os cursos de aperfeiçoamento são importantes e podem ter êxito na medida em que há a participação voluntária dos docentes, existência de material de apoio e que atendam grupos de professores de uma mesma escola (CUNHA; KRASILCHICK, 2000). Nesse sentido, a universidade pode contribuir oferecendo oportunidades/cursos de aperfeiçoamento, aproximando a academia com a escola.

É fato de que existe um afastamento entre a academia e a escola. Para muitos professores, as pesquisas desenvolvidas nas universidades (o conhecimento produzido) são desnecessárias para a condução de suas aulas no Ensino Fundamental e Médio. Tampouco procuram saber ou conhecer pesquisas realizadas em instituições de Nível 
Superior, para melhorar o seu desempenho e suas práticas em sala de aula (ZEICHNER, 1998).

De acordo com Zeichner (1998, p. 3), há uma falta de esforço em diminuir as diferenças entre pesquisador e professor, pois dificilmente os professores da rede escolar são convidados pelos pesquisadores em participar intelectualmente na escolha das questões a serem investigadas, na elaboração do projeto de pesquisa, na coleta e análise dos dados e, até mesmo no compartilhamento dos resultados. Pesquisas são realizadas em instituições de ensino Fundamental e Médio, mas nem sempre os resultados obtidos são revelados ou repassados aos docentes das escolas.

Esse distanciamento existente poderia ser diminuído, especialmente na disciplina de História, pois muitos projetos de pesquisas desenvolvidas em universidades abordam a História Regional e Local, ou seja, tem seu foco para a região onde a instituição está inserida, mas o conhecimento gerado não chega à escola.

Assim, os professores da Educação Básica, longe do ambiente acadêmico, recorrem com frequência para o livro didático como recurso principal para suas aulas. O mesmo normalmente é de fácil entendimento, pois para quem tem formação na área, uma leitura prévia pode ser suficiente, para ensinar o conteúdo ministrado aos estudantes.

No Brasil, o livro didático tem se transformado no principal instrumento a auxiliar o trabalho dos professores em sala de aula, sendo o recurso didático mais explorado na maioria das salas de aula do Ensino Fundamental e Médio. Assim, o mesmo já está incorporado na cultura escolar brasileira (SILVA, 2012). Entretanto, os livros didáticos não abordam temas e assuntos para ensinar a História Regional e Local, pois esses conteúdos não são contemplados nos mesmos. A procura desse material didático vai além das bibliotecas escolares, podendo chegar até a universidade (PAIM; PICOLLI, 2007).

Além do livro não contemplar temas regionais, percebe-se ainda que, em algumas partes do Brasil, um aspecto bastante comum é a deficiência de bibliografia atualizada, ou seja, não dispõem de publicações recentes de cunho acadêmico. Isso faz com que o conteúdo se enquadre em referências desatualizadas (CUNHA; KRASILCHIK, 2000).

Vinculado a essa deficiência, por muitas décadas a historiografia tradicional elegeu, na sua concepção, atores que fizeram a "história do Brasil", enquanto que algumas etnias que participaram diretamente da formação da nação foram esquecidas. Pouco se falava dessas sociedades (indígenas, escravizados africanos, entre outros) excluídas.

Segundo Martins (2009), na região Sul do Brasil, em áreas onde há predominância da colonização alemã e italiana, por exemplo, as memórias históricas recaem sobre os imigrantes europeus e seus descendentes. Para a autora, "A presença indígena apenas se 
faz notar quando o 'barbarismo' dos nativos é apresentando para contrapor-se (e exaltar) o valor do pioneirismo civilizador dos imigrantes" (MARTINS, 2009, p. 164).

Mesmo que ainda existam lacunas sobre o conhecimento que se tem a respeito dos povos nativos da América, a historiografia renovou-se nas últimas décadas. No Brasil, se observa um crescimento na medida em que houve um incremento dos estudos envolvendo as populações indígenas. Entretanto, isto ainda pouco repercute em relação do que se ensina nas escolas brasileiras (MARTINS, 2009).

Para Martins (2009, p. 164), muitos livros didáticos tratam a temática superficialmente pois, "[...] aos indígenas permanecem reservadas apenas as páginas iniciais dos conteúdos de 'história do Brasil', que se encerram com a contribuição da cultura indígena e sua herança”. É veiculada a imagem de um índio genérico, estereotipado, que vive nu na mata e mora em ocas e tabas, uma forma pouco adequada, de se tratar essas populações. Segundo Medeiros (2012), notadamente o período que o ensino de História lembra é o colonial. São necessárias novas fontes, novos materiais.

A formulação do material didático está vinculada com a escassez de obras de cunho regional científico. Segundo Lia, Costa e Monteiro (2013, p. 44), "Quanto mais carente é um determinado assunto de informações nos materiais didáticos, mais interessante é a proposta de produzir sobre o mesmo". Nesse sentido, a Educação Patrimonial pode colaborar, por meio de atividades que permitam que o ensino da História Regional ou Local adquira uma nova conotação, pois o estudo das mesmas influi e ajuda o estudante a compreender a sua história e consequentemente sua realidade (CÉRRI, 1996). Para que os estudantes possam compreender de forma satisfatória as relações existentes entre a região onde vivem e o global, os estudos regionais e locais são muito pertinentes (PAIM; PICOLLI, 2007), auxiliando assim, os professores a ministrarem suas aulas com conteúdo.

\section{A HISTÓRIA REGIONAL E A EDUCAÇÃO PATRIMONIAL}

A importância da História Regional está no sentido de permitir ao historiador uma aproximação maior com o seu objeto de estudo. O seu estudo deixa de ser baseado apenas em temas distantes para se incorporar aos processos históricos de um determinado espaço (NEVES, 2002; OLIVEIRA, 2003; SILVA, 2012).

A História Regional tem como enfoque histórico determinado espaço, tomando-o como delimitação para o objeto de estudo. É aquela que analisa processos históricos em áreas geográficas não muito extensas, em pequenos e médios municípios (HORN; 
GERMINARI, 2010).O historiador analisa e estuda uma região específica ou as relações sociais desse espaço (BARROS, 2004; CAPRINI, 2016).

Segundo Schiavon e Santos (2011), a investigação e a construção do conhecimento histórico, tendo como base elementos da cultural local favorecem para um maior envolvimento dos estudantes, uma vez que passam a (re)significar os elementos estruturantes desta cultura. Para os pesquisadores (2011, p. 5),

\begin{abstract}
A apropriação e a valorização desta cultura - múltipla e plural - são fundamentais à construção da cidadania e, nesta direção, o estudo da História do município permite problematizar as relações socioambientais, a dinâmica do tecido social e a complexidade destas dinâmicas as quais estão inseridas, a partir de uma análise em que os estudantes podem facilmente projetar as categorias trabalhadas nas práticas escolares.
\end{abstract}

A História Regional, segundo Silva (2006, p. 96), "A narrativa deixa de ser fundamentada em temas distantes para se incorporar aos fenômenos históricos da região, consequentemente do município". Para Samuel (1990), o passado se torna mais imediato.

$\mathrm{Na}$ medida que os professores da Educação Básica trabalham com elementos da História Regional, vão provocando reflexões dos alunos em relação à sua comunidade e às relações socioambientais nas quais estão inseridos. Os alunos constroem narrativas conforme suas experiências familiares e do grupo de convivência, estabelecem relações entre as temporalidades e os espaços vividos e não vividos (CAINELI, 2001; SCHIAVON; SANTOS, 2011).

Assim, a cultura local e regional passam a ter um novo sentido implicando em ações para que possam ser absorvidas pela Educação Formal. E, uma delas pode ser a Educação Patrimonial.

A Educação Patrimonial permite, segundo Schiavon e Santos (2011), uma apropriação na construção do conhecimento, a partir de atividades relacionadas com o patrimônio cultural da comunidade, "[...] tendo em vista a interação direta com a cultura local, fortalecendo, desta forma, o pertencimento àquela comunidade".

Segundo Horta (2000), o conhecimento crítico e a apropriação consciente pela comunidade do seu patrimônio tornam-se indispensáveis para o processo de preservação sustentável dos bens culturais de uma comunidade, bem como, o fortalecimento dos sentimentos de identidade e cidadania.

A Educação Patrimonial é um instrumento de "alfabetização cultural". Permite fazer uma leitura do mundo que está à sua volta e, como consequência, compreender o universo sociocultural e da trajetória histórico-temporal em que está inserido, reforçando a autoestima dos indivíduos e comunidade e à valorização da cultura (HORTA; GRUNGBERG; MONTEIRO, 1999, p. 6). 
Sendo assim, a partir desses fatores que interferem diretamente nas aulas, especialmente para aqueles professores que ministram a disciplina de História, foi desenvolvido o projeto que propiciou novos conhecimentos e aos docentes que lecionam para estudantes do Ensino Fundamental e Médio da região Vale do Taquari/RS, qualificando assim, suas aulas.

\section{ATIVIDADES PROPOSTAS AOS PROFESSORES DA EDUCAÇÃO BÁSICA DO VALE DO TAQUARI}

O projeto1 "Educação Patrimonial: difusão do conhecimento, valorização e desenvolvimento social" foi dividido em duas partes. A primeira a elaboração de um livro, material didático, sobre o povoamento/colonização da região Vale do Taquari/RS. Na segunda etapa foram oferecidas oficinas aos professores nas escolas que solicitaram o projeto abordando e aprofundando o tema do livro, bem como salientando a importância da conscientização e preservação do Patrimônio Cultural.

Assim, em função de uma histórica carência de material didático de cunho científico, que privilegie o tema: o povoamento regional, antes e depois da chegada dos colonizadores europeus, foi desenvolvido um livro com ilustrações, que englobou todas as sociedades que se estabeleceram, ou que circularam no território dos municípios inseridos na região Vale do Taquari/RS.

\section{O CONTEÚDO DO LIVRO}

A publicação, cujo título é "O povoamento do Vale do Taquari, Rio Grande do Sul", é uma síntese sobre os grupos humanos que circularam ou colonizaram a região. Ricamente ilustrado, foi dividido em dez capítulos abordando a participação de todas as sociedades, pré-coloniais e coloniais que contribuíram para a formação social, política e econômica regional.

Os primeiros grupos humanos que circularam pelo Vale do Taquari foram os Paleoíndios. Sociedades nômades que percorrem o território de norte a sul, deixando suas marcas nos inúmeros sítios arqueológicos. De acordo com as datações realizadas, o grupo

\footnotetext{
1 O projeto fez parte do Estágio Pós-Doutoral (KREUTZ, 2017) desenvolvido junto ao Programa de PósGraduação em Ensino da Universidade do Vale do Taquari.
} 
pode ter se estabelecido no espaço entre 9000 a 2000 anos AP (RIBEIRO, et. al., 1989; WOLF, 2016).

Alguns séculos mais tarde, os Jê Meridionais iniciam o processo de colonização do Vale. Sociedades horticultoras, também conhecidas como construtores das casas subterrâneas, na linguagem popular "buracos de bugre", se estabelecem ao norte do território do Vale do Taquari. As pesquisas realizadas em sítios arqueológicos do referido grupo, demonstram que os mesmos habitaram o espaço entre os séculos IX e XIV (WOLF, 2016).

Ainda antes da chegada dos colonizadores europeus, o território do Vale do Taquari recebeu novos migrantes. Por volta do século XIII, grupos Guarani se estabelecem nas planícies situadas ao longo dos recursos hídricos, entre eles, o Rio Taquari e o Forqueta. Esses grupos horticultores escolheram o centro e o sul do Vale, para erguer suas aldeias e desenvolver sua cultura (SCHNEIDER, 2014; KREUTZ, 2015).

Dessa forma, as sociedades indígenas que povoaram o Vale do Taquari foram os Paleoíndios, Jê Meridionais e os Guarani. Com a chegada do europeu, a partir do século $\mathrm{XVII}$, a paisagem regional muda significativamente.

Nesse sentido, a Companhia de Jesus teve um papel preponderante, pois com a finalidade de manter o território sob domínio da Coroa espanhola e ao mesmo tempo aldear e "evangelizar" o maior número de indígenas possíveis, ergueram entre as décadas de 1620 e 1630, uma série de aldeamentos no então Rio Grande do Sul.

Os primeiros europeus de que se tem conhecimento, a partir da documentação existente2, prospectaram o Vale do Taquari foram sacerdotes da Companhia de Jesus. Em 1635, dois religiosos circularam pela região, porém, não fundaram nenhuma redução. No mesmo período adentraram o atual estado, os bandeirantes paulistas, cuja finalidade das expedições eram o aprisionamento de indígenas, os quais eram enviados a Capitania de São Vicente (São Paulo) para trabalhar nas fazendas (KREUTZ, 2015).

Um século depois, meados do século XVIII novos imigrantes europeus se estabelecem no Vale do Taquari, iniciando a colonização. Os primeiros são os portugueses e, que com eles, são trazidos os escravizados africanos. A partir de meados do século XIX, mais imigrantes europeus se instalam no Vale. Duas etnias se destacaram, os alemães, a partir de 1850 e, mais tarde, os italianos, na década de 1880. Imigrantes de outras etnias também se estabelecem como franceses, holandeses e suíços, porém, em número inferior.

${ }^{2}$ A documentação que aqui se refere são as Cartas Ânuas. Documentos redigidos pelos religiosos para seus superiores dando conta de suas atividades no novo continente. 
Os textos do livro produzido, "O povoamento do Vale do Taquari, Rio Grande do Sul" foram elaborados tendo como base trabalhos acadêmicos, teses (CHRISTILLINO, 2010; KREUTZ, 2015; WOLF, 2016), dissertações (CHRISTILLINO, 2004; FIEGENBAUM, 2009; WOLF, 2012; SCHNEIDER, 2014; PIRES, 2016), monografias (ECKHARDT, 2005; ROSA, 2014), artigos (RIBEIRO, et al, 1989; FIEGENBAUM; SCHNEIDER; MACHADO, 2005; MARQUES, 2006; GOMES; LAROQUE, 2010; MOREIRA; CARDOSO, 2012) e livros (FALEIRO, 1996; RELLY; MACHADO; SCHNEIDER, 2009; KREUTZ, et al, 2011), cujo foco principal é a região Vale do Taquari/RS. Destaca-se que foram utilizados em sua maioria, textos produzidos a partir de projetos de pesquisa vinculados ao Laboratório de Arqueologia da Universidade do Vale do Taquari, entre os anos de 2001 a 2016.

\section{A FORMAÇÃO CONTINUADA: AS OFICINAS REALIZADAS COM OS PROFESSORES}

Para viabilizar o projeto, foram feitos contatos com a Coordenadoria Regional de Educação3 - 3 $3^{\mathrm{a}} \mathrm{CRE}$, com sede na cidade de Estrela/RS, que tem sob sua jurisdição as escolas estaduais dos municípios que compõem a região Vale do Taquari. Após a apresentação do projeto e do material para coordenação da $3^{\text {a }}$ CRE, a própria Coordenadoria entrou em contato com todas escolas estaduais apresentando o projeto. A partir disso, foram agendadas oficinas com as escolas que manifestaram interesse.

Do mesmo modo, foram realizadas visitas às Secretarias Municipais de Educação com o mesmo propósito, apresentar o projeto e desenvolver atividades com os professores municipais. Por fim, o projeto igualmente foi oferecido para uma instituição federal de ensino e educandários privados, os quais também demonstram interesse de proporcionar novos conhecimentos aos seus professores.

Além de professores, também foram atendidos estudantes e bolsistas do Programa Institucional de Bolsa de Iniciação à Docência - PIBID do Curso de História da Universidade do Vale do Taquari e estudantes de duas escolas estaduais do Curso Normal/Magistério.

O projeto atendeu professores que ministravam disciplinas no Ensino Fundamental e Médio, sendo que as oficinas foram realizadas diretamente nas dependências das escolas

\footnotetext{
${ }^{3}$ Conforme a Secretaria Estadual de Educação (2017, on-line), "A Secretaria da Educação do RS tem uma estrutura que conta com 30 coordenadorias regionais sob coordenação direta do governo do Estado. Cada coordenadoria é responsável pelas políticas relacionadas as suas regiões, tendo como atribuições coordenar, orientar e supervisionar escolas oferecendo suporte administrativo e pedagógico para a viabilização das políticas da secretaria. [...] A Coordenadoria Regional de Educação representa a secretaria na área de sua jurisdição, tendo como atribuições também o fornecimento de pessoal qualificado para atuar nas escolas e a gestão de seus recursos financeiros e de infraestrutura".
} 
participantes do projeto. As atividades nas escolas tinham a duração de um turno, ou cinco horas-aula, as quais foram ministradas pelo Estagiário Pós-Doutorado do Programa de PósGraduação em Ensino da Universidade do Vale do Taquari, e acompanhadas por bolsistas de iniciação científica.

No início da atividade, todos os participantes da oficina ganhavam um livro. Em seguida, em forma de exposição oral, seguida de diálogo eram abordados os temas constantes do livro, bem como a importância da sensibilização e proteção para o Patrimônio Cultural da região e as pesquisas desenvolvidas na Instituição.

Durante as conversas, verificou-se, muitas vezes, a surpresa e o primeiro impacto com uma "outra versão" da história, em que personagens como os indígenas e negros escravizados começam a tomar assento na História Regional e Local. Uma história, ainda perpetuada pelo ufanismo proposto pelos antigos "historiadores" sem formação na área em específico, do contexto da imigração europeia dos séculos XVIII e XIX.

\section{RESULTADOS ALCANÇADOS}

Entre janeiro a agosto de 20174 foram atendidos um total de 132 professores de escolas públicas estaduais e 19 da rede municipal. Esses docentes estão em escolas dos municípios de Lajeado, Estrela, Cruzeiro do Sul, Relvado, Travesseiro, Progresso e Capitão. No mesmo período foram atendidos 47 professores de dois educandários da rede privada e 7 docentes pertencentes a uma escola federal, todos com sede no município de Lajeado/RS. Também foram atendidos 12 bolsistas, graduandos do Curso de História da Universidade do Vale do Taquari, participantes do PIBID e 160 estudantes do Curso Normal/Magistério de duas escolas da rede pública estadual dos municípios de Lajeado e Estrela/RS.

Dentre outros resultados alcançados, destaca-se elementos teóricos da história acadêmica, alicerçada pelas pesquisas apoiadas por instituições de fomento público, como a CAPES e CNPq. Nesses fundamentos, apresentou-se assuntos como: a História Antiga e Arqueológica especialmente das povoações e assentamentos das sociedades indígenas falantes do tronco linguístico Tupi-Guarani e Jê, moradores antigos da região. Assuntos como cultura material e noções teóricas e práticas de sensibilização para o Patrimônio Cultural foram debatidos baseados em dados locais e regionais.

\footnotetext{
4 O projeto foi desenvolvido entre agosto/2016 e julho/2017, entretanto, na instituição federal as atividades foram realizadas na primeira semana de agosto/2017.
} 
A premissa básica e mais importante nessas ações foi refletir sobre a história global, mas alavancando a história local e inserindo-a num plano em que os sítios arqueológicos ou as "antigas casas de pedra ou em estilo enxaimel" dos primeiros colonizadores europeus estão conectados com os contextos históricos, os quais muitas vezes não estão nos livros didáticos ou não são levados ao universo da escola por falta de subsídios.

Outros aspectos da História Regional similarmente são tratados, como o processo da escravidão negra e o pós abolição na região. Trata-se de um assunto "confuso" para a historiografia regional, pois praticamente até a primeira década do ano 2000, esse tema não era abordado na sociedade regional, tampouco nas escolas. Com o avanço das investigações no campo da História e Arqueologia da universidade comunitária regional, a temática foi sendo elucidada, e as antigas fazendas, senzalas e quilombos começam a revelar-se no contexto do século XIX. Nesse ínterim, o processo das movimentações de imigrantes europeus, a partir do século XVIII, passam a fazer parte desse contexto e 0 tratamento que se tenta dar, está relacionado à história global.

Da mesma forma, o século XVII e XVIII passam a compor um cenário de contatos interétnicos na região. A História Regional passa a ser composta pelas tentativas de agrupamentos missioneiros, a passagem dos jesuítas, a introdução de elementos construtivos na paisagem, a vinda dos lusos açorianos para instalar a economia dos ervais e gado, bem como do comércio da madeira.

\section{CONSIDERAÇÕES FINAIS}

Os professores da Escola Básica no Brasil, em especial a pública, enfrentam uma série de problemas e que incidem diretamente no ensino. Entre as dificuldades que se apresentam estão a excessiva carga horária, as classes com um número expressivo de estudantes, os baixos salários, a formação inadequada dos professores, pois os cursos de formação oferecidos são precários em relação as possibilidades de instrumentalização para a prática docente e a falta de material didático diversificado e de boa qualidade disponível para o educador (CUNHA; KRASILCHIK, 2000).

Para minimizar as dificuldades que norteiam o dia a dia do professor foi desenvolvido o projeto "Educação Patrimonial: difusão do conhecimento, valorização e desenvolvimento social", o qual cumpriu com os objetivos propostos, ou seja, a elaboração de material didático, a realização de oficinas como formação continuada para os professores, difusão do conhecimento gerado na universidade e por último, a aproximação da academia com a escola. Assim, a partir das experiências construídas ao longo das atividades propostas 
durante o período do projeto, possibilitaram o aprimoramento profissional dos professores da Educação Básica.

Durante as oficinas também foram apresentados outros Projetos de Pesquisa desenvolvidos na Instituição. Dessa maneira pretendeu-se despertar o interesse dos professores às pesquisas e ao mesmo tempo aproximar a academia com a escola. Conforme Cunha e Krasilchick (2000), envolver o professor na pesquisa significa mudar seus paradigmas, pois os professores são formados a ensinar e não para pesquisar.

É claro que, ao se produzir um material didático, persistem lacunas, pois ao se produzir o material sobre o povoamento regional, privilegiou-se em um primeiro momento um conteúdo básico, ou seja, uma base de pesquisa aos professores das escolas públicas e privadas. Da mesma forma, as atividades realizadas com os professores nas escolas. Estas necessitavam de um período bem maior para as oficinas, porém, em virtude de dificuldades em que o magistério vem passando no Brasil, tiveram que ser mais condensadas. Mesmo assim, a repercussão do projeto foi positiva.

Por fim, mas ainda não acabado, ao oferecer o projeto aos professores que ministram aulas ao Ensino Fundamental e Médio, se oportuniza um novo conhecimento, aprofundado e refinado aos docentes, em especial aos que ministram aulas de História, permitindo uma aprendizagem mais qualificada em sala de aula. Acredita-se que o processo do aprender e ensinar o conteúdo da disciplina de História remete a repensar o processo de reconhecimento das identidades étnicas e culturais, privilegiando as necessidades e possibilidades de reflexões sociais e de igualdade. $O$ docente, nessa perspectiva, está mais apto a manipular as informações dispostas e com isso desenvolver habilidades e capacidades em seus alunos para que o processo de aprendizagem seja crítico e atinente às realidades impostas do mundo contemporâneo.

\section{REFERÊNCIAS}

ARÓSteGUI, J. A Pesquisa Histórica. São Paulo: Edusc, 2006.

BARROS, J. D' A. O campo da História: especialidades e abordagens. Petrópolis: Vozes, 2004.

CAINELLI, M. A relação entre o conteúdo e metodologia no ensino de História: apontamentos para repensar a formação de professores, bacharéis ou profissionais da História. Saeculum - Revista de História, João Pessoa, n. 6, 2001. 
CAPRINI, A. B. A. Pesquisa em História Regional: aspectos conceituais e metodológicos. 2016. Disponível em: <http://www.ilb.ufop.br/lllsimposio/64.pdf>. Acesso em 20 jun. 2018.

CÉRRI, L. F. Regionalismo e ensino de História. In: BITENCOURT, Circe M. (Org.). Anais do 2ํㅡㄹ Encontro Perspectivas do Ensino de História. São Paulo: FEUSP, 1996.

CHESNEAUX, J. Devemos fazer tábua rasa do passado? Sobre a história e os historiadores. São Paulo: Ática, 1995.

CHRISTILLINO, C. L. Estranhos em seu próprio chão: o processo de apropriações e expropriações de terras na província de São Pedro do Rio Grande do Sul. (O vale do Taquari no período de 1840 - 1889). 2004. Dissertação, 374f. (Mestrado em História) Universidade do Vale do Rio dos Sinos, São Leopoldo, 2004.

Litígios ao sul do Império: a Lei de Terras e a consolidação política da Coroa (1850-1880). 2010, 353 f. Tese (Doutorado em História) - Universidade Federal Fluminense, Rio de Janeiro, 2010.

CUNHA, A. M. O.; KRASILCHICK, M. A formação continuada de professores de ciências: percepções a partir de uma experiência. In: REUNIÃO ANUAL DA ANPED, 23, 2000, Caxambú. Anais... Caxambu, 2000.

ECKHARDT, R. R. Zoneamento ambiental do Vale do Taquari. 2005. 105 f. Monografia (Curso de Biologia) - Centro Universitário Univates, Lajeado, 2005.

FALEIRO, S. R. Lajeado: perfil histórico étnico-social (do período indígena a colonização). Lajeado, 1996.

FIEGENBAUM, J. Um assentamento Tupiguarani no Vale do Taquari/RS. 2009. Dissertação, 221f. (Mestrado em História) - Universidade do Vale do Rio dos Sinos, São Leopoldo, 2009.

FIEGENBAUM, J.; SCHNEIDER, P.; MACHADO, N. G. O passado histórico revisto pela arqueologia no Vale do Taquari/RS: ocupação pré-colonial. Revista História. Cruz Alta: Unicruz, n. 6, 2005

FISCARELLI, R. B. O. Material didático e prática docente. Revista Ibero-Americana de Estudos em Educação, Araraquara, v. 2, n. 1, 2007.

GOMES, V. F.; LAROQUE, L. F. S. História e cultura dos italianos e seus descendentes: o costume do filó em localidades do Vale do Taquari/RS. Destaques Acadêmicos, Lajeado, n. 2, 2010. 
HORN, G. B.; GERMINARI, G. D. Ensino de história e seu currículo: teoria e método. Petrópolis: Vozes, 2010.

HORTA, M. L. P. Fundamentos da educação patrimonial. Ciências \& Letras. Porto Alegre, n. 27, 2000.

HORTA, M. L. P.; GRUNGBERG, E.; MONTEIRO, A. Q. Guia básico de educação patrimonial. Brasília: IPHAN/Museu Imperial, 1999.

KREUTZ, M. R. Movimentações de populações Guarani, séculos XIII ao XVIII - Bacia Hidrográfica do Rio Taquari, Rio Grande do Sul. 2015. 330f. Tese (Doutorado em Ambiente e Desenvolvimento) - Centro Universitário UNIVATES. Lajeado, 2015.

Relatório Estágio Pós-Doutorado. Programa de Pós-Graduação em Ensino. Lajeado, Universidade do Vale do Taquari, 2017.

KREUTZ, M. R.; SCHNEIDER, P.; MACHADO, N. T. G.; SCHNEIDER, F. Arroio do Meio: entre rios e povos. Lajeado: Editora Univates, 2011.

LE GOFF, J. História e Memória. Campinas: Unicamp, 1990.

LIA, C. F.; COSTA, J. P.; MONTEIRO, K. M. N. A produção de material didático para o ensino de História. Revista Latino-Americana de História, São Leopoldo, v. 2, n. 6, 2013.

MARQUES, T. M. F. A companhia de navegação fluvial de Jacob Arnt no Vale do Taquari - RS. Navigator, Rio de Janeiro, v. 2, n. 3, 2006.

MARTINS, M. C. B. As sociedades indígenas e a escola. Antíteses, Londrina, v. 2, n. 3, 2009.

MEDEIROS, J. S. Povos indígenas e a lei n 11.645: (in)visibilidades no ensino da história no Brasil. In: BERGAMASCHI, M. A.; DALLA ZEN, M. I. H.; XAVIER, M. L. M. F. Povos indígenas \& Educação, Porto Alegre: Mediação, 2012.

MOREIRA, P. R. S.; CARDOSO, R. R. O cotidiano insubmisso: insurreição escrava, políticas senhoriais e comunidades negras em cativeiro (Taquari - RS - Século XIX). In: SIMPÓSIO NACIONAL DE HISTÓRIA CULTURAL, 6, 2012. Teresina. Anais... Teresina: Universidade Federal do Piauí, 2012.

NEVES, E. F. História Regional e Local no Brasil: fontes e métodos da pesquisa histórica regional e local. Feira de Santana/ Salvador: UEFS/Editora Arcádia, 2002. 
OLIVEIRA, A. M. C. S. Recôncavo Sul: terra, homens, economia e poder no século XIX, Salvador: Editora UNEB, 2003.

PAIM, E. A.; PICOLLI, V. Ensinar história regional e local no ensino médio: experiências e desafios. História e Ensino. Londrina, v. 13, 2007.

PIRES, K. D. O trabalho escravo e suas implicações na paisagem urbana e rural de Taquari, Estrela e Santo Amaro/RS - final do século XIX. 2016. 182 f. Dissertação (Mestrado em Ambiente e Desenvolvimento) - Centro Universitário Univates, Lajeado, 2016.

RELLY, E.; MACHADO, N. T.G.; SCHNEIDER, P. Do Taiaçuapé a Colinas. Lajeado, Editora da UNIVATES, 2008.

RIBEIRO, P. A. M.; KLAMT, S. C.; BUCHAIM, J. J. S.; RIBEIRO, C. T. Levantamentos arqueológicos na encosta do planalto entre os vales dos Rios Taquari e Caí. Revista do CEPA, Santa Cruz do Sul, v. 16, n. 19, out. 1989.

ROSA, L. W. A variabilidade gráfica da cerâmica pintada Guarani nos sítios RS-T 101 e RS-T 114. 2014. 75 f. Monografia (Curso de História) - Centro Universitário Univates, Lajeado, 2014.

SAMUEL, R. História local e História oral. Revista Brasileira de História. São Paulo, v. 9, n. 19, 1990.

SCHIAVON, C. G. B.; SANTOS, T. F. Educação Patrimonial: um caminho à discussão sobre a cidadania a partir da história local. 2011. Disponível em:

<http://repositorio.furg.br/bitstream/handle/1/3407/Educa\%C3\%A7\%C3\%A30\%20patrimon ial>. Acesso em 23 jun. 2018.

SCHNEIDER, F. Interpretação do espaço Guarani: um estudo de caso no Sul da Bacia Hidrográfica do Rio Forqueta, Rio Grande do Sul, Brasil. 2014. 220f. Dissertação (Mestrado em Ambiente e Desenvolvimento) - Centro Universitário Univates, Lajeado, 2014.

SECRETARIA Estadual de Educação. Coordenadoria Regional de Educação. Governo do Estado do Rio Grande do Sul. 2017. Disponível em:

<http://serviços.educacao.rs.gov.br/pse/html/cre.jsp?ACAO=acao1\&CRE=0>. Acesso em 06 nov. 2017.

SILVA, L. C. B.; A importância do estudo da História Regional e Local no Ensino Fundamental. Textura, Cruz das Almas, v. 1, n. 1, p. 95-100, 2006. 
A importância do estudo da História Regional e Local no Ensino Fundamental.

In: ENCONTRO ESTAUDAL DE HISTÓRIA. 3, 2012, Vitória da Conquista. Anais... Vitória da Conquista, 2012.

SOUZA, S. E. O uso de recursos didáticos no ensino escolar. In: ENCONTRO DE PESQUISA EM EDUCAÇÃO, 1, 2007, Maringá. Anais... Maringá, 2007.

WOLF, Sidnei. Paisagens e sistemas de assentamento: um estudo sobre a ocupação humana pré-colonial na Bacia Hidrográfica do Rio Forqueta, RS. 2012. 187 f. Dissertação (Mestrado em Ambiente e Desenvolvimento) - Centro Universitário Univates, Lajeado, 2012.

Arqueologia Jê no Alto Forqueta e Guaporé/RS: um novo cenário para um antigo contexto. 2016. 353f. Dissertação (Doutorado em Ambiente e Desenvolvimento) Centro Universitário Univates, Lajeado, 2016.

ZEICHNER, K. M. Para além da divisão entre professor-pesquisador e pesquisador acadêmico In: GERALDI, C. M.; FIORENTINI, D.; PEREIRA, E. M. A. (Orgs.) Cartografia do trabalho docente: professor(a)-pesquisador(a). Campinas: Mercado de Letras, 1998. 